\title{
0 trabalho docente sob a ótica da síndrome de burnout
}

\author{
Jéssica Utiyama* \\ Cláudia Chueire de Oliveira*
}

\section{Resumo}

\begin{abstract}
Este estudo empreende uma reflexão acerca do trabalho docente na educação superior, no curso de Pedagogia. $\mathrm{O}$ trabalho apresenta uma discussão relativa à síndrome de burnout na realidade dos docentes. Os objetivos foram reconhecer, no trabalho do docente do curso de Pedagogia, uma possível sobrecarga de atividades e funções; identificar se os professores percebem que têm sobrecarga de funções; conceituar a síndrome de burnout; analisar, por meio das falas dos professores do curso de Pedagogia, quais são as consequências boas e ruins do trabalho docente e as dificuldades existentes na profissão. A metodologia teve como base os pressupostos da pesquisa qualitativa, com auxílio de questionário para a coleta de dados na realidade. Os resultados obtidos apontam que o conjunto de incumbências dos docentes de Pedagogia evidenciam a sobrecarga de trabalho docente e que esses professores possuem características e consequências identificadas com elementos da síndrome de burnout.
\end{abstract}

Palavras-chave: Ensino superior. Prática pedagógica. Síndrome de burnout. Trabalho docente.

\section{Introdução}

A pesquisa desenvolvida buscou trazer à comunidade acadêmica uma reflexão relativa ao trabalho docente na educação superior, partindo, para tanto, das seguintes perguntas: os docentes do ensino superior sentem-se sobrecarregados pelo seu trabalho? O que pensam sobre essa situação? Quantos docentes do curso de Pedagogia possuem alguma característica da síndrome de burnout? O objetivo geral desta pesquisa constituiu-se em reconhecer, no trabalho do docente do curso de Pedagogia, uma possível sobrecarga de atividades e funções. Os objetivos especí-

Recebido em 12 de outubro de 2012. Aprovado em 18 de fevereiro de 2013.

http://dx.doi.org/10.5335/rep.2013.3515

Graduada em Pedagogia pela Universidade Estadual de Londrina (UEL). E-mail je_utiyama@hotmail.com

** Doutora em Educação. Docente Adjunta do Departamento de Educação da UEL. E-mail cchueire@uel.br 
ficos foram: identificar se os professores percebem que têm sobrecarga de funções; conceituar a síndrome de burnout; analisar, por meio das falas dos professores do curso de Pedagogia, quais são as consequências boas e ruins do trabalho docente e as dificuldades existentes na profissão.

Para este estudo, a metodologia de pesquisa aproximou-se das propostas da abordagem qualitativa, com auxílio de questionário como instrumento para coleta de dados. Segundo Lüdke (1986), o estudo qualitativo é caracterizado por se desenvolver em situações naturais, é rico em dados descritivos, tem um plano aberto e flexível e focaliza a realidade. Para proceder à coleta de dados, foram entregues aos setenta docentes do curso de Pedagogia um questionário previamente estruturado, composto por cinco perguntas, que buscaram conhecer as percepções acerca do trabalho, da carga horária cumprida, dos aspectos positivos e negativos da profissão e dos motivos causadores de estresse. Os depoimentos foram analisados e interpretados, considerando os trabalhos de Carlotto (2002), Cunha (2005), Tardif e Lessard (2005), Codo (2006), entre outros.

\section{0 curso de Pedagogia}

Para compreender o trabalho docente no curso de Pedagogia da Universidade Estadual de Londrina (UEL), é necessário retomar parte da história da Pedagogia no Brasil. Segundo Furlan (2008), no início do século XX, surgiram movimentos sociais que buscavam provocar transformações no âmbito educacional brasileiro, destacando-se, dentre eles, o movimento dos Pioneiros da Escola Nova, o qual lutava pela educação e implantação de universidades no Brasil. O movimento reformador escolanovista, do início do século XX, refletia a necessidade de reencontrar a vocação da escola na sociedade urbana de massas, industrializada e democrática. Esse movimento criou o contexto para a fundação da Faculdade de Filosofia e Letras, um dos pilares históricos da universidade brasileira, que possibilitou, também, o surgimento do curso de Pedagogia, cujo objetivo era formar professores para o ensino secundário.

Do final do século XIX até 1930, no Brasil, os professores foram formados pela Escola Normal (FURLAN, 2008, p. 3864). De acordo com a autora, o primeiro curso superior de formação de professores no país foi criado em 1935, na Universidade do Distrito Federal. No entanto, muitos reconhecem a Faculdade Nacional de Filosofia da Universidade do Brasil, fundada em 1939, como a primeira instituição oficial de formação de professores. O curso de Pedagogia foi estruturado em três anos, dedicados às disciplinas de conteúdo - ou seja, os fundamentos da educação - e um ano para a didática, destinada a todos os cursos de licenciatura. 
O sistema $3+1$ ficou bastante conhecido. O bacharelado, nos três primeiros anos, preparava o indivíduo para ocupar cargos técnicos da educação; e a licenciatura, ao final do quarto ano, visava à formação para a docência. Esse tipo de sistema reduziu a didática ao ensino técnico, o que possivelmente originou a dicotomia entre teoria e prática nos cursos de formação de professores (FURLAN, 2008, p. 3865).

Diante das novas demandas do mercado de trabalho, no contexto de tecnicismo dos anos 1960, a formação do pedagogo em especialista dividiu as atividades de orientação, administração, supervisão e inspeção do sistema escolar. O curso de Pedagogia, também, foi marcado por transformações obtidas por meio de movimentos sociais contra a ditadura do regime militar. O movimento dos educadores dos anos 1980 abrangeu o âmbito nacional. Somente em 2006, porém, as Diretrizes Curriculares Nacionais (DCNs) para o curso de Pedagogia foram homologadas, abrangendo a formação da docência, a elaboração e a execução de atividades educativas, bem como a gestão e a avaliação de sistemas e instituições de ensino.

O artigo $2^{\circ}$ da Resolução Conselho Nacional de Educação (CNE)/Conselho Pleno (CP) n. 1 passou a determinar o curso de Pedagogia como formação inicial para docência na educação infantil, nos anos iniciais do ensino fundamental, nos cursos de ensino médio (na modalidade normal) e em cursos de educação profissional, na área de serviços e apoio escolar, bem como em outras áreas nas quais fossem previstos conhecimentos pedagógicos, tendo como principal local de formação as universidades. Outra mudança foi a extinção das habilitações de supervisão escolar, orientação educacional e administração escolar.

O curso de Pedagogia na cidade de Londrina foi criado pelo governo do Estado do Paraná no início de 1961. Conforme Abbud (2007), o curso de Pedagogia na Universidade Estadual de Londrina tinha como características gerais uma formação única em licenciatura. Em 1991, foram elaborados os primeiros Projetos Político-Pedagógicos (PPPs) da UEL. A Pedagogia apresentou as seguintes habilitações: magistério das matérias pedagógicas do $2^{\circ}$ grau e orientação educacional; supervisão escolar e administração escolar $1^{\circ}$ e $2^{\circ}$ graus; magistério para a pré-escola e magistério para as séries iniciais do ensino fundamental. Em 2005, são extintas as habilitações e é garantida a formação em três áreas: a docência - base da proposta pedagógica; a gestão pedagógica; e a pesquisa, ou seja, formação do licenciado pedagogo com a possibilidade de atuação na docência e na gestão pedagógica, tendo a pesquisa educacional como um dos eixos norteadores.

Em 2010, por força de lei, há nova reformulação. O curso passa a ter a duração mínima de quatro anos e meio, ofertado nos períodos matutino e noturno, abrangendo a formação do educador para a educação formal e a educação não formal. 
Após muitas alterações durante sua história, o currículo atual determina que o curso de Pedagogia da Universidade Estadual de Londrina seja divido em três campos principais: a docência, a gestão pedagógica e a pesquisa. Seja no campo da docência, seja no da gestão, a pesquisa tem sido introduzida e desenvolvida concomitantemente. O curso de Pedagogia da UEL entende ser necessário que o futuro profissional da educação acumule experiência nas referidas áreas por meio dos estágios supervisionados, na educação infantil, séries iniciais e gestão no espaço escolar e nos espaços não escolares. Para integralização do curso, requer-se que seja apresentado pelo aluno um Trabalho de Conclusão de Curso (TCC).

\section{A formação de professores para a educação superior}

A palavra "docência" significa ensinar, instruir, mostrar, indicar, dar a entender. Passou a ser utilizada a partir de 1916 (VEIGA, 2005). A autora expande o conceito de docência, trabalho dos professores, para além da ministração de aulas, porque, ao longo do tempo e com as novas condições de trabalho que surgem, o conjunto de funções docentes foi se complexificando.

As funções do professor de educação superior, segundo as condições atuais, amparadas pela Lei de Diretrizes e Bases da Educação (LDB), Lei n. 9.394/96, art. 13, incluem o docente participar da elaboração do projeto pedagógico; elaborar e cumprir o plano de trabalho; zelar pela aprendizagem dos alunos; estabelecer estratégias de recuperação para alunos de menor rendimento; ministrar os dias letivos e horas-aula estabelecidos; participar integralmente dos períodos dedicados ao planejamento, à avaliação e ao desenvolvimento profissional. Indica-se que, para a realização dessas funções, são necessários conhecimentos específicos, para exercê-lo adequadamente, ou, no mínimo, a aquisição dos conhecimentos e das habilidades vinculadas à atividade docente para melhorar sua qualidade. A docência universitária exige, ainda, a integração entre ensino, pesquisa e extensão, assim como a produção de conhecimentos, sua socialização e a execução da atividade reflexiva e problematizadora do futuro profissional.

Pachane (2006) explica que, em 1999, o Plano Nacional de Graduação (PNG) foi aprovado. O PNG é um projeto em construção estruturado em torno de princípios que requerem um novo perfil docente: formação científica na área de conhecimento; pós-graduação stricto sensu, preferencialmente no nível de doutorado; domínio do complexo processo histórico de constituição de sua área; ampla e crítica compreensão dos métodos que produziram o conhecimento acumulado; e competência pedagógica (FORGRAD, 2004). As metas do PNG também indicam que as instituições de ensino superior (IES) devem institucionalizar programas de forma- 
ção pedagógica continuada, provendo-se meios para adoção e absorção de novas tecnologias e metodologias de ensino.

O PNG enfatiza que o docente da educação superior deve possuir qualificações de mestre e/ou doutor, havendo prioridade no magistério aos doutores. No entanto, não se exige apenas a titulação, mas também se deve dominar conhecimentos de um campo científico específico, assim como conhecimentos pedagógicos. Isto é, precisa apresentar competência pedagógica e científica. De acordo com Veiga (2005), a formação não pode se esgotar em diplomas quando se pretende o desenvolvimento profissional que supere momentos fragmentados e descontínuos.

Para isso, Anastasiou (2006) aponta para a necessidade de reflexão a respeito da insuficiência na formação pedagógica do futuro docente, que, ao ingressar na docência universitária, acaba incorporando posturas e metodologias de seus ex-formadores. A literatura indica que, na maioria das vezes, há um ensino repetitivo, focado apenas na exposição do conteúdo sem oportunizar a troca de informações com os estudantes, reforçando a memorização do conteúdo para aprovação nos exames.

Para a superação de tais condições, é necessária a reestruturação dos PPPs dos cursos. O conhecimento científico, objeto de trabalho docente, deve ser orientado por lógica, necessidades e compromissos próprios da universidade como instituição social, cujo princípio é a formação, criação, reflexão e crítica autônoma. Anastasiou (2006) destaca, ainda, que as práticas de estudo independente e a construção da autonomia intelectual e profissional têm sido pontuadas como fundamentais nos perfis dos acadêmicos, considerando-se que os conhecimentos, as experiências e vivências adquiridos na vida profissional e social, relevantes para a área de formação, devem ser trazidos à sala de aula e compartilhados.

Por meio das reflexões até aqui apresentadas acerca do universo docente na educação superior, é possível perceber que o docente possui muitas responsabilidades na formação de novos profissionais. Formar professores para a educação superior é mais que apresentar êxito na pesquisa, é realizar o ensino e a extensão na mesma proporção e intensidade.

\section{A síndrome de burnout}

Há inúmeros fenômenos que cercam e afetam o trabalho do professor no cotidiano. A literatura identifica o crescimento e a expansão da síndrome de burnout como um dos mais recorrentes. Burnout é um termo norte-americano cujo significado é exaustão, fadiga; apagar-se, esgotar-se; e, de maneira mais literal, expressa "perder o fogo", "perder a energia" ou "queimar (para fora) completamente" (CODO, 2006, p. 238). A síndrome de burnout, de acordo com estudos já desenvol- 
vidos por Codo (2006), relaciona-se ao estresse laboral crônico, ou seja, um estado psicoemocional que envolve atitudes e condutas negativas em relação aos alunos, à organização e ao trabalho. Refere-se a um estado resultante do trabalho exaustivo, deixando de lado até mesmo as próprias necessidades pessoais.

É possível detectar o aparecimento de três fatores principais que compõem a síndrome de burnout: a despersonalização, a exaustão emocional e o baixo envolvimento pessoal no trabalho. A despersonalização é a substituição do vínculo afetivo com outras pessoas pelo racional, pela crítica exacerbada de tudo e de todos; "perda do sentimento de que estamos lidando com outro ser humano" (CODO, 2006, p. 242). O professor começa a desenvolver atitudes negativas, críticas aos alunos, atribuindo-lhes seu próprio fracasso e tratando-os friamente como objetos. A exaustão emocional é o desgaste do vínculo afetivo, esgotamento da energia física e/ou mental, de maneira que "o professor nesta situação se sente totalmente exaurido emocionalmente, devido ao desgaste diário ao qual é submetido no relacionamento com seus alunos" (CODO, 2006, p. 241). O baixo envolvimento pessoal diz respeito à baixa realização pessoal no trabalho. $O$ trabalhador não se percebe capaz de atingir os objetivos aos quais se propôs, o que lhe causa um sentimento de impotência, de incapacidade de realizar algo com que sonhou. Trata-se de um conflito que leva "[...] a pessoa a avaliar a si própria negativamente, particularmente com respeito ao próprio trabalho com os alunos. Seu trabalho perde o sentido" (CODO, 2006, p. 242). Suas relações interpessoais se tornam contatos com objetos, desprovidas de calor humano, o que o leva a sofrer de ansiedade, melancolia, baixa autoestima, sentimento de exaustão física e/ou emocional.

De acordo com Codo (2006), há pesquisas que consideram a influência do ambiente de trabalho como fator desencadeador desse tipo de síndrome. No campo educacional, a indisciplina nas salas de aula, a violência, a falta de segurança, a administração insensível aos problemas do professor, a burocracia do processo de trabalho, os pais omissos, as transferências involuntárias, as críticas da opinião pública, as classes superlotadas, a falta de autonomia, os salários inadequados, a falta de perspectivas de ascensão na carreira, a falta de rede social de apoio e o preparo inadequado são apontados como causadores do burnout. Segundo Farber (1991 apud CODO, 2006), há, ainda, a questão salarial, o desrespeito, a depreciação, a ineficácia e a insegurança no valor do seu trabalho, que também são problemas que contribuem para o estresse e o burnout de professores.

Em especial, as áreas de saúde e educação mostraram índices mais elevados de sintomas da síndrome. O termo surgiu para exprimir o sentimento de profissionais que trabalhavam diretamente com pacientes dependentes de substâncias químicas e que desistiam diante da frustração do árduo trabalho. Esse tipo de sín- 
drome pode ser decorrente de ambientes que exerçam pressões sobre o indivíduo e de situações que possam acarretar um estresse de caráter persistente.

Farber (1991 apud CARLOTTO, 2002) enfatiza que há diferença de gênero. Os professores do sexo masculino mostram-se mais vulneráveis ao burnout que as mulheres, as quais são mais flexíveis e abertas para lidar com as pressões do processo de ensino. Já Etzion (1987 apud CARLOTTO, 2002) menciona que há diferença no período de atuação entre os professores. Professores mais novos apresentam maior incidência, pois idealizam excessivamente a profissão.

Schwab e Iwanicki (1982 apud CARLOTTO, 2002) e Woods (1999 apud CARLOTTO, 2002) informam que o nível de ensino do professor também pode ser um determinante da síndrome; ou seja, professores de ensino fundamental e médio podem apresentar mais atitudes negativas em relação aos alunos e menor frequência de sentimentos no desenvolvimento profissional do que professores de educação infantil. No entanto, em se tratando das possíveis causas da síndrome de burnout, o mau relacionamento entre professor e aluno mostra-se como uma das principais. Abel e Sewell (1999 apud CARLOTTO, 2002) relatam que a relação com os familiares dos alunos também pode se mostrar problemática e estressante, seja pela comum falta de envolvimento da família no processo educacional, seja pelo excesso de proteção ao filho, colocando no professor a culpa pelos problemas apresentados no processo de ensino-aprendizagem.

Todos esses fatores, além de trazerem como consequência a desistência do ator social no trabalho, acarretam danos que afetam o trabalho profissional, as relações com a família, com colegas e com todas as outras pessoas com as quais convive, resultando, ainda, na permanência e na reprodução do sistema educacional que hoje impera.

\section{0 que dizem os professores sobre o trabalho docente no curso de Pedagogia}

Foi elaborado e entregue um questionário a setenta professores do curso de Pedagogia, tendo sido devolvidos 22. A maioria dos docentes afirma que trabalha em torno de doze horas ou mais, e seis deles sinalizam que suas jornadas de trabalho são de oito horas. Quando indagados se alguma vez já se sentiram sobrecarregados pelo trabalho, vinte responderam que sim, justificando que dores no corpo ou problemas de saúde, cansaço, estresse e ansiedade eram os sintomas que mais se destacavam. Para exemplificar, reproduzo alguns depoimentos sobre as consequências da sobrecarga de trabalho: 
"Cansaço, dores de cabeça, dores nos olhos, visualização fraca, dores no corpo" (Professor 11);

"Sempre... Engordei, fiquei mais ansioso, tive problemas com a esposa por falta de convivência à noite e nos fins de semana" (Professor 10);

"Cansaço, desânimo, vontade de não vir trabalhar" (Professor 13).

Com base no depoimento dos docentes, é possível inferir que o professor acaba fazendo muito mais do que as condições de trabalho permitem, e, em razão disso, pode ser levado a um estado de cansaço, abatimento, perdendo, inclusive, a vontade de ensinar. Farber (1984 apud CODO, 2006) expressa que diagnosticar algum sentimento de burnout em um professor não significa que este esteja sofrendo da síndrome em questão, mas que já a experimentou em algum momento. No entanto, como alerta Codo (2006), trata-se de uma síndrome que vai avançando com o tempo, corroendo devagar o ânimo do educador; conforme a metáfora, o fogo vai se apagando devagar.

Aprofundando a reflexão acerca da fala do Professor 10 - "Sempre... Engordei, fiquei mais ansioso, tive problemas com a esposa por falta de convivência à noite e nos fins de semana" -, é possível verificar que a situação apresentada é semelhante à que Vasques-Menezes, Codo e Medeiros (2006) apresentam em seus estudos. O profissional passa a maior parte de seu tempo produtivo no trabalho ou envolvido com ele. Muitas vezes, a atividade profissional rouba uma boa parcela do tempo que poderia ser dedicado à família, de modo que se perdem detalhes do crescimento dos filhos, a atenção aos pais fica limitada, assim como o cuidado dos relacionamentos pessoais.

Famílias em que o casal possui filhos pequenos estão mais sujeitas a esses conflitos. Além disso, há que se considerar que a disponibilidade para o cuidado dos filhos e da casa afeta, sobretudo, o trabalho das mulheres, visto que ainda representam a maioria do magistério. No quadro de docentes do curso de Pedagogia da Universidade Estadual de Londrina, objeto de estudo desta pesquisa, parece não ser diferente, visto que há, atualmente, em 2012, 78 docentes do sexo feminino e oito do sexo masculino.

Entretanto, ainda conforme Vasques-Menezes, Codo e Medeiros (2006), esse tipo de conflito pelo qual passam os docentes da educação superior pode ser superado com compreensão, respeito, reconhecimento e flexibilidade de horário, fundamentais para a saúde do profissional do magistério.

Foi solicitado aos docentes que assinalassem três entre as dez alternativas apresentadas, indicando quais seriam os desencadeadores do estresse na profissão. As opções mais indicadas foram, em primeiro lugar, o excesso de atividades docen- 
tes e a burocracia do processo de trabalho; em segundo lugar, a indisciplina/indiferença dos alunos nas salas de aula; e, em terceiro lugar, os salários inadequados.

Em outra questão, os docentes foram indagados sobre os aspectos negativos do trabalho. São apresentados, na sequência, depoimentos que exemplificam as duas situações, ou seja, fatores que desencadearam stress e aspectos negativos da docência:

"O excesso de atividades (pedagógicas e burocráticas) que afetam o tempo que deveria ser dedicado ao trabalho especificamente pedagógico, à pesquisa e à extensão. O professor universitário virou um 'faz tudo', com excesso de reunião, comissões, bancas, leituras, pareceres, análise de documentos, tendo pouco tempo para levar os conhecimentos produzidos na universidade a serviço da comunidade. Trabalhamos $8 \mathrm{~h} /$ dia na universidade e levamos uma boa parte do trabaIho para casa" (Professor 21);

"A falta de reconhecimento social da profissão, excesso de trabalhos para ser [sic] realizados em casa, falta de interesse por parte dos alunos" (Professor 17);

"Ter que utilizar sábados, domingos e feriados para dar conta das atividades que assumo e dos compromissos que assumo com os alunos, como o de devolver semanalmente, com feedback, as tarefas que solicito, também semanalmente" (Professor 8).

Adentrar na questão da burocratização do processo de trabalho significa, para Cunha (2005), ter em vista o contexto da crise econômica e do avanço das políticas neoliberais que vem disseminando a ideologia do mercado, dos discursos da excelência e da privatização na educação. Se para a burocracia quantidade do trabalho significa qualidade, o docente tem de se ocupar cada vez mais com atividades, tanto dentro quanto fora da instituição, o que revela a segunda maior causa de stress nessa profissão: o excesso de atividades docentes.

Tardif e Lessard concebem a docência como "um trabalho de limites imprecisos e variáveis de acordo com os indivíduos e as circunstâncias, e também segundo os estabelecimentos e os quarteirões e localidades" (2005, p. 112). Com isso, descrevem a docência como um trabalho parcialmente flexível, porque algumas atividades educativas possuem uma duração determinada legalmente pela organização escolar e outras podem variar quanto à duração e à frequência, de acordo com a experiência do professor, de sua relação e seu comprometimento com o trabalho etc. Alguns depoimentos já explicitados anteriormente evidenciam essa situação, como, por exemplo: "Ter que utilizar sábados, domingos e feriados para dar conta das atividades que assumo e dos compromissos que assumo com os alunos, como o de devolver semanalmente, com feedback, as tarefas que solicito, também semanalmente" (Professor 8) e "Sempre... Engordei, fiquei mais ansioso, tive problemas com a esposa por falta de convivência à noite e nos fins de semana" (Professor 10).

Alguns, ainda, comprometem a sua constante formação profissional, que poderia ser desenvolvida com cursos de aperfeiçoamento, de formação específica, 
atividades paraescolares ou sindicais, das associações profissionais, dentre outras atividades. Certas exigências específicas que afetam a carga de trabalho também demandam uma maior disponibilização de energia de determinados professores, como o trabalho com alunos com dificuldades de aprendizagem ou alunos com necessidades educativas especiais.

Oliveira (2011) apresenta que é condição essencial ao exercício docente a formação do aluno como um sujeito que não reproduza a sociedade vigente, ou que somente reflita sobre ela, mas que esteja disposto e seja capaz de promover transformação. Cunha afirma que essa é a maior contradição que os docentes universitários vivem atualmente, pois somente assim é possível "perceber os processos humanos em movimento e apostar neles como embriões de mudança" (2005, p. 66).

Por fim, a questão 4 solicitava que os docentes descrevessem os aspectos positivos do seu trabalho, sendo os mais comentados: o contato com os alunos, a realização profissional e o desenvolvimento humano e profissional dos alunos. A seguir, são transcritos alguns dos depoimentos para exemplificar:

"Gosto do que faço. Tenho ótimos feedbacks dos alunos. Isso é um fator de autoestima e realização profissional e também pessoal" (Professor 8).

"Conseguir conscientizar o aluno sobre a importância da escola e do estudo para sua vida pessoal e profissional. Refletir sobre a importância do próprio trabalho para uma sociedade cada vez mais exigente" (Professor 1 ).

“Possibilidade de parceria com os estudantes. Participar de um processo de construção e reelaboração do conhecimento. Colaborar com a formação de profissionais importantes, comprometidos com a sociedade" (Professor 20).

Como se pode observar por meio dos depoimentos, a relação com os alunos é essencial ao trabalho docente, pois, conforme Tardif e Lessard (2005), ensinar é trabalhar com seres humanos, sobre seres humanos e para seres humanos. E para que isso ocorra, é necessário, também, que se conserve a alegria na prática docente e para com seus alunos. Apesar dos inúmeros aspectos desmotivadores encontrados no desrespeito à educação, aos educandos, aos educadores e às educadoras, banalizando a sensibilidade e o bem-querer da própria prática educativa, torna-se cada vez mais necessária a alegria do docente em sua profissão. Assim escreve Freire: "É esta força misteriosa, às vezes chamada vocação, que explica a quase devoção com que a grande maioria do magistério nele permanece, apesar da imoralidade dos salários. E não apenas permanece, mas cumpre como pode seu dever. Amorosamente, acrescento" (2006, p. 142).

O docente é um profissional que lida com pessoas, que lida com sonhos e esperanças de outros indivíduos. Como pode, então, ele próprio perder a esperança de uma sociedade melhor? Freire (2006) afirma que não se pode negar a quem 
sonha o direito de sonhar e é por meio dos sonhos que a mudança se torna possível. Aquele que sonha busca a realização de seus sonhos pela transformação da sua realidade. Com base nessa premissa, é possível crer no que Freire explicita como saber fundamental: "mudar é difícil, mas é possível” (2006, p. 79). E é necessário. Nas palavras de Alves, "foi assim que se construiu a ciência: não pela prudência dos que marcham, mas pela ousadia dos que sonham. Todo conhecimento começa com o sonho" (2008, p. 87).

Como apontam Tardif e Lessard (2005), muitos professores optaram por essa profissão devido ao gosto por ajudar os colegas ainda quando estudantes, o que revela que essa escolha emerge da história pessoal e escolar dos indivíduos. Alguns professores ainda demonstram afeto quanto à profissão, pois o remetem à própria infância, quando ensinar era um sonho que cultivavam até a sua concretização. De acordo com os mesmos autores, os professores se engajam afetivamente em seu trabalho com o ensino, pois possuem um sentimento, um desejo de transmitir conhecimentos e contribuir para a formação de sujeitos, de profissionais que formarão e transformarão a sociedade. Contribuir para a expansão de conhecimentos já existentes e para a construção de novos, que, juntos, constituirão o profissional consciente da necessidade de uma constante formação intelectual, é a fonte energizante do trabalho docente.

\section{Considerações finais}

Com base na análise realizada neste estudo, foi possível compreender a constituição atual e as transformações e redefinições pelas quais o trabalho docente vem passando. São situações que permeiam a formação e a prática do professor como sujeito atuante e agente formador, diretamente influenciado pelas modificações da sociedade e pelas demandas do mercado de trabalho.

O curso de Pedagogia que habilitava o profissional para as funções de docência, ou supervisão, ou orientação, ou administração escolar, a partir de 2006, passa a ser uma licenciatura que forma o profissional pedagogo "generalista" para exercer todas as funções. Entre as questões que permanecem, estão: até que ponto essa alteração legal se mostrou benéfica ao profissional da educação? Poderia essa nova Pedagogia ser um aspecto instigante no fenômeno da sobrecarga do trabalho desse profissional, uma vez que suas funções foram ampliadas? Tanto para aqueles que exercem a docência quanto para aqueles que atuam na função de pedagogos, é importante analisar o percurso da profissão que se exerce, para buscar compreender as transformações do passado que afetam o trabalho do presente. $\mathrm{O}$ momento 
requer que formandos e formadores percebam como as modificações ocorridas na história da Pedagogia afetam o exercício das funções profissionais e a vida pessoal. As novas exigências da produtividade requerem que o docente universitário apresente suas produções em ritmo acelerado para evidenciar a qualificação do corpo docente (SANTOS, 2008). No caso da Pedagogia, além da complexidade das funções de docência e pesquisa, o docente possui atribuições de supervisor dos estágios obrigatórios na educação infantil, nas séries iniciais e na gestão no espaço escolar e nos espaços não escolares, incluindo orientação de TCCs. A diversidade de atuação é, portanto, ampla e maior que em muitas outras profissões, o que vem a possibilitar a incidência de uma sobrecarga de trabalho.

Os estudos de Carlotto (2002) e Codo (2006) trouxeram ao conhecimento a existência de uma síndrome que explica as características e consequências provenientes da sobrecarga de trabalho: a síndrome de burnout, que induz o profissional a desistir de seu trabalho sem abrir mão de seu emprego. O contato direto com pessoas, o não reconhecimento pelo seu duro trabalho, a necessidade de lidar com o sistema burocrático universitário, o stress enfrentado nas situações de trabalho são alguns dos aspectos de que derivam os sintomas da síndrome de burnout, que são: a despersonalização, a exaustão emocional e o baixo envolvimento pessoal no trabalho. As possíveis causas da síndrome são inúmeras e diversas, e, embora haja diferença nos sexos, ambos - homens e mulheres - estão sujeitos a desenvolvê-la.

Por meio dos depoimentos dos próprios docentes de Pedagogia, foi possível compreender, em certa medida, a realidade dos professores e comprovar a presença de sintomas da síndrome de burnout em seu cotidiano. A desmotivação, a frustração e o stress foram características percebidas nas falas dos professores participantes.

Contudo, os mesmos docentes que indicaram ter desenvolvido sintomas da síndrome de burnout, em algum momento de suas carreiras, foram os que demonstraram ainda existir em si resquícios de esperança. Esperança de transformação, por meio da elaboração e reelaboração do conhecimento, bem como da possibilidade de formar profissionais comprometidos.

Ao final deste trabalho, com o aprofundamento do tema, houve um evidente crescimento não apenas acadêmico como também pessoal. Este trabalho de pesquisa é o primeiro marco de uma longa carreira profissional. Apesar de se mostrar um caminho repleto de novos desafios e nem sempre com circunstâncias motivadoras, os depoimentos dos docentes, repletos de sentimentos, sonhos e esperanças, permitem perceber a importância do docente e de suas funções. A importância de se buscar fazer, individual e coletivamente, um trabalho de qualidade que possa, consequentemente, ser gerador de uma educação de qualidade na formação dos futuros docentes. Compreendeu-se, também, que são fundamentais o trabalho de 
investigação e a reflexão das práticas pedagógicas quando se pretende vencer os desafios propostos. Para finalizar as reflexões desta pesquisa, é necessário ressaltar que compete à nova geração de pedagogos concretizar a profissão e a profissionalidade da categoria.

\section{The teaching work from the perspective of burnout}

\section{Abstract}

This study intends to bring to the academic community a reflection on teaching in higher education in the Pedagogy Course. The paper presents a discussion on the burnout syndrome in teachers' reality. The objectives were to recognize, in the work of teachers in the pedagogy course, a possible overload of activities and functions; identify if teachers realize they have overhead of functions; conceptualize burnout; analyze, through the statements of the Pedagogy's teachers, what are the consequences of good and bad teaching and the difficulties existing in the profession. The methodology was based on the assumptions of qualitative research with the support of a questionnaire to collect data. Obtained results pointed out that the set of assignments of Pedagogy teachers evidence the overload of teacher's work and that they have characteristics and consequences identified with elements of the burnout syndrome.

Keywords: Burnout syndrome. Higher education. Pedagogical practice. Teacher work.

\section{Referências}

ABBUD, M. L. M. História da educação no curso de pedagogia - 1960 a 1990 - FFCLL/UEL. In: CONGRESSO NACIONAL DE EDUCAÇÃO - Educere - Saberes Docentes, n. 7, 2007, Curitiba. Anais... Curitiba: Champagnat, 2007, p. 955-965.

ALVES, R. Ensinar o que não se sabe. In: A alegria de ensinar. 12. ed. Campinas, SP: Papirus, 2008. p. 83-93.

ANASTASIOU, L. G. C. Docência na educação superior. In: RISTOFF, D.; SEVEGNANI, P. (Org.). Docência na educação superior. Brasília: Instituto Nacional de Estudos e Pesquisas Educacionais Anísio Teixeira, 2006. v. 5. p. 147-171. (Coleção Educação Superior em Debate).

BRASIL. Ministério da Educação e Cultura. Lei n. 9.394/96 - Lei de Diretrizes e Bases da Educação Nacional. Brasília, 1996.

. Secretaria da Educação. Resolução $C N E / C P$ no 1, art. 2. Brasília: Conselho Nacional de Educação - Conselho Pleno, 2006.

CARLOTTO, Mary S. A síndrome de burnout e o trabalho docente. Psicologia em Estudo, Maringá, v. 7, n. 1, p. 25, 2002.

CODO, W. (Coord.). Educação: carinho e trabalho. 4. ed. Petrópolis, RJ: Vozes; Brasília: Confederação Nacional dos Trabalhadores em Educação/Universidade de Brasília/Laboratório de Psicologia do Trabalho, 2006. 
CUNHA, M. I. da (Org.). Formatos avaliativos e concepção de docência. Campinas, SP: Autores Associados, 2005.

FORGRAD (Org.). Resgatando espaços e construindo ideias: ForGrad 1997 a 2004. 3.ed. ampl. Uberlândia, MG: Edufu, 2004. Disponível em: <http://www.forgrad.com.br/documentos/publicacoes/publicacao_7.pdf>. Acesso em: 12 set. 2012.

FURLAN, C. M. A. História do curso de pedagogia no Brasil: 1939-2005. In: CONGRESSO NACIONAL DE EDUCAÇÃO - EDUCERE - Formação de Professores, n. 8, 2008, Curitiba. Anais... Curitiba: Champagnat, 2008, p. 3862-3875.

FREIRE, P. Pedagogia da autonomia: saberes necessários à prática educativa. São Paulo: Paz e Terra, 2006.

LÜDKE, M.; ANDRÉ, M. E. D. A. Pesquisa em educação: abordagens qualitativas. São Paulo: EPU, 1986.

OLIVEIRA, C. C. A ação docente sob o foco da formação: uma discussão necessária. In: OLIVEIRA, D. E. M. B; SANTOS, A. R. J.; REZENDE, L. A. (Org.). Formação de professores e ensino: aspectos teórico-metodológicos. Londrina, PR: UEL, 2011. p. 1-11.

PACHANE, G. G. Teoria e prática na formação de professores universitários: elementos para discussão. In: RISTOFF, D.; SEVEGNANI, P. (Org.). Docência na educação superior. Brasília: Instituto Nacional de Estudos e Pesquisas Educacionais Anísio Teixeira, 2006. p. 97-145. v. 5. (Coleção Educação Superior em Debate).

SANTOS, L. L.C. P. Dilemas e perspectivas na relação entre ensino e pesquisa. In: ANDRÉ, M. (Org.). O papel da pesquisa na formação e na prática dos professores. Campinas, SP: Papirus, 2008. p. 11-25.

TARDIF, M.; LESSARD, C. A carga de trabalho dos professores. In: O trabalho docente: elementos para uma teoria da docência como profissão de interações humanas. Petrópolis, RJ: Vozes, 2005.

VASQUES-MENEZES, Iône; CODO, Wanderley; MEDEIROS, Larissa. O conflito entre o trabalho e a família e o sofrimento psíquico. In: CODO, Wanderley (Coord.). Educação: carinho e trabalho. 4. ed. Petrópolis, RJ: Vozes; Brasília: Confederação Nacional dos Trabalhadores em Educação/Universidade de Brasília/Laboratório de Psicologia do Trabalho, 2006. p. 237-254.

VEIGA, I. P. A. Docência universitária na educação superior. In: RISTOFF, D.; SEVEGNANI, P. (Org.). Docência na educação superior. Brasília: Instituto Nacional de Estudos e Pesquisas Educacionais Anísio Teixeira, 2005. v. 5. p. 85-96. (Coleção Educação Superior em Debate). 